\title{
PHÁT HIỆN VÀ NGHIÊN CÚU VĂN HÓA SA HUỲNH (1909 - 2019)
}

\author{
Lâm Thị Mỹ Dunga*
}

${ }^{a}$ Truoòng Đại học Khoa học Xã hội và Nhân Văn, Đại học Quốc gia Hà Nội, Hà Nội, Việt Nam

"Tác giả liên hệ: Email: bebimkch@gmail.com

Lịch sử bài báo

Nhận ngày 14 tháng 04 năm 2019

Chỉnh sửa ngày 28 tháng 07 năm 2019 | Chấp nhận đăng ngày 05 tháng 08 năm 2019

\section{Tóm tắt}

Năm 1909, một thông báo ngắn do Vinet (1909) công bố về "Phát hiện một kho chum gốm có khoảng 200 chiếc nằm cách mặt đất không sâu trong một cồn cát vùng ven biển $\mathrm{Sa}$ Huỳnh". Đây là công bố đầu tiên, mở đầu cho hàng loạt nghiên cứu và khai quật khảo cổ học vào nhũng năm sau đó trên địa bàn huyện Đức Phổ (Quảng Ngãi). Đến năm 1923, Labarre tới Sa Huỳnh khai quật, kết quả này đã được Parmentier (1923) công bố trong tác phẩm "Kho mộ chum Sa Huỳnh ở Quảng Ngãi, xú An Nam" trong Tập san của Truờng Viễn đông Bác cổ (tập 24), xuất bản taii Hà Nội, hiện vật trong đọt khai quật đuợc luu giũ tại Bảo tàng Lịch sủ Việt Nam cho đến tận ngày nay. Sau đọt khai quật này, nhiều nghiên cứu khác được công bố, đáng chú ý là thuật ngũ Văn hóa Sa Huỳnh đã được Colani (1936) đề xuất. Sau năm 1975, bên cạh một số di tích Sa Huỳnh ở Quảng Ngãi, các nhà khảo cổ hoc trong và ngoài nước đã phát hiện và nghiên cứu nhiều di tích tiền Sa Huỳnh, Sa Huỳnh và kiểu/giống Sa Huỳnh ở nhiều địa phuoong khác nhau thuộc miền Trung, Tây Nguyên, và Nam Bộ Việt Nam. Bài viết giới thiệu nhũng thành tựu nổi bật của các nhà khảo cố về văn hóa Sa Huỳnh tù khi phát hiện đến nay. Những nhận thức mới về đặc trung, tính chất, niên đại, nguồn gốc, chủ nhân và mối quan hệ văn hóa cũng được luận bình thêm trong nghiên cứu; Một số vấn đề đặt ra cần tiếp tục nghiên cứu nhằm bảo tồn và phát huy giá trị của di sản cũng được đề cạp.

Từ khóa: Sa Huỳnh cổ điển; Thời đại đồ sắt; Văn hóa Sa Huỳnh; Văn hóa Tiền Sa Huỳnh.

DOI: http://dx.doi.org/10.37569/DalatUniversity.9.3.557(2019)

Loại bài báo: Bài báo nghiên cứu gốc có bình duyệt

Bản quyền @ 2019 (Các) Tác giả.

Cấp phép: Bài báo này được cấp phép theo CC BY-NC-ND 4.0 


\title{
DISCOVERING AND RESEARCH OF SA HUYNH CULTURE (1909 - 2019)
}

\section{Lam Thi My Dung ${ }^{*}$}

${ }^{a}$ The University of Social Sciences and Humanities, Vietnam National University, Hanoi, Vietnam

"Corresponding author: Email: bebimkch@gmail.com

\section{Article history}

Received: April 14 $4^{\text {th }}, 2019$

Received in revised form: July $28^{\text {th }}, 2019 \mid$ Accepted: August $5^{\text {th }}, 2019$

\begin{abstract}
In 1909, a short report by Vinet (1909) announced the "Discovery of a depot containing about 200 earthen mortuary containers which was buried not deep in the sand dune in the coastal area of Sa Huynh". This was the first announcement, opening a series of excavations and archaeological research in later years in Ducpho district (Quangngai). In 1923, Labarre went to Sa Huynh to carry out the excavation, and the excavation results were reported in Parmentier's work "The depot of Sa Huynh jar burials in Quangngai, An Nam" in the journal of the EFEO (volume 24) published in Hanoi. The artifacts obtained from this excavation have been kept at the Museum of Vietnamese History to the present day. After this excavation, many other studies were published, and it is worthy of note that in 1936 the term Sa Huynh culture was proposed by Colani (1936). After 1975, along with the sites belonging to Sa Huynh culture in Quangngai, Vietnamese and foreign archaeologists have recognized and studied many Pre Sa Huynh, Sa Huynh, and Sa Huynhlike cultural sites in various localities in the Central Highlands and Southern Vietnam. The article describes the outstanding achievements of the archaeologists regarding the $\mathrm{Sa}$ Huynh culture since its discovery. New insights and knowledge about the nature, characteristics, chronology, origins, owners and cultural relations are also further commented on in this study. Some issues that need further research to conserve and promote the value of the heritage are also mentioned.
\end{abstract}

Keywords: Classic Sa Huynh; Iron age; Pre Sa Huynh culture; Sa Huynh culture.

DOI: http://dx.doi.org/10.37569/DalatUniversity.9.3.557(2019)

Article type: (peer-reviewed) Full-length research article

Copyright $\odot 2019$ The author(s).

Licensing: This article is licensed under a CC BY-NC-ND 4.0 


\section{MỞ ĐẦU}

Văn hóa Sa Huỳnh là một nền văn hóa khảo cổ có niên đại sơ kỳ thời đại Đồ sắt ở Duyên hải Miền Trung (Việt Nam). Địa điểm Sa Huỳnh là khu mộ táng được phát hiện lần đầu tiên vào năm 1909, tại một cánh đồng muối Sa Huỳnh ngay cửa sông Trà Bồng, xã Phổ Hạnh, huyện Đức Phổ (Quảng Ngãi). Thuật ngữ "Văn hóa Sa Huỳnh" lần đầu tiên được Colani (1937) đề xuất, đến nay giới khảo cổ học thừa nhận sự tồn tại của một văn hóa khảo cổ riêng biệt - "Văn hóa Sa Huỳnh"1.

Kể từ khi phát hiện đến nay, nhiều kết quả và tư liệu mới được công bố đã đem lại những nhận thức mới về nền văn hóa độc đáo này. Hiện nay nội hàm văn hóa $\mathrm{Sa}$ Huỳnh được dùng để chỉ cho một nhóm các di tích khảo cổ có niên đại khoảng 500 năm BC (Before Christ) đến thế kỷ I - II AD (Auno Domini), phân bố trên dải đất Miền Trung với nhiều dạng địa phương khác nhau. Các nhà chuyên môn còn gọi là "Bức khảm Sa Huỳnh". Có thể nói, tính đa dạng của văn hóa Sa Huỳnh xuất phát từ nền tảng đa dạng của thời kỳ Tiền $\mathrm{Sa}$ Huỳnh trước đó, là cơ sở của sự hình thành các tiểu quốc Lâm Âp - Champa sau này.

Bài viết này trình bày những thành tựu nghiên cứu nổi bật về văn hóa Sa Huỳnh và những nhận thức mới, như: Tính chất, niên đại, và chủ nhân nội hàm văn hóa $\mathrm{Sa}$ Huỳnh ở Việt Nam. Đưa ra vài nhận xét, nhận thức và thảo luận nhằm góp thêm tư liệu cho vấn đề nghiên cứu cội nguồn, nội hàm văn hóa, hậu duệ của Sa Huỳnh cũng như mối quan hệ của văn hóa Sa Huỳnh với các văn hóa đồng đại.

\section{TỪ NHỬNG PHÁT HIÊN ĐÀU TIÊN ĐẾN ĐINH DANH VÀ DIỄN GIẢI MỘT NỀN VĂN HÓA KHẢO CỔ - VĂN HÓA SA HỪNH}

\subsection{Những khám phá bước đầu về văn hóa Sa Huỳnh (1909 - 1960)}

Qua việc phân tích các tài liệu đã nghiên cứu trước đây, tác giả Lâm (2009b) đã nêu ý kiến về những khám phá bước đầu về văn hóa Sa Huỳnh:

Trong giai đoạn 1909 - 1960, việc phát hiện nghiên cứu, và định danh nội hàm của nền văn hóa Sa Huỳnh thuộc về những học giả người Pháp. Cũng trong giai đoạn này nhiều cuộc khai quật đã được tiến hành ở tỉnh Quảng Ngãi và Bình Thuận. Muộn hơn chút nữa là các cuộc khai quật mộ chum ở khu vực Đông Nam Bộ. Đến nay, vẫn còn không ít ý kiến phê phán phương pháp khai quật của các học giả người Pháp, hay cũng như quan điểm truyền bá luận của họ trong việc diễn giải mã di tích và, di vật. Nhưng không thể phủ nhận tư liệu khai quật ở các địa điểm này đã làm sáng tỏ đáng kể một số khía cạnh của văn hóa Sa Huỳnh, như: Niên đại, táng thức, loại hình hiện vật... (đoạn 1).

${ }^{1}$ Địa điểm Sa Huỳnh được lấy tên để định danh cho tất cả các di tích, di vật có chung đặc trưng, tính chất, niên đại, phân bố liền khoảnh đều thuộc nội hàm của nền văn hóa Sa Huỳnh. 
Bên cạnh nghiên cứu điền dã, người Pháp cũng bước đầu nghiên cứu và đặt văn hóa Sa Huỳnh trong bối cảnh Đông Nam Á. Đáng chú ý, tiếp cận liên văn hóa đã được Solheim (1959) áp dụng trong những nghiên cứu về đồ gốm. Khái niệm "truyền thống gốm Sa Huỳnh-Kalanay" sau đồi thành "phức hệ gốm Sa HuỳnhKalanay" mà Solheim (1959) đưa ra còn gặp nhiều ý kiến trái chiều nhưng không phải là không có cơ sở. Những tư liệu nghiên cứu gần đây ở địa điểm Hòa Diêm (Khánh Hòa), Giồng Nổi (Bến Tre), Giồng Lớn (Bà Rịa - Vũng Tàu)... đã góp phần làm rõ bản chất và niên đại của truyền thống hay phức hệ này, đặc biệt là quan hệ giữa hai truyền thống này ở Đông Nam Á trong giai đoạn Tiền sử và Sơ sử (đoạn 2)

\subsection{Chặng đường từ năm 1975 - đầu thập niên 90 của thế kỷ XX}

Đây là thời kỳ tập trung nghiên cứu và có những cuộc khai quật lớn. Những vấn đề về nguồn gốc, niên đại, nội hàm thời gian và không gian của văn hóa Sa Huỳnh... được quan tâm từ nhiều góc độ và áp dụng các quan điểm nghiên cứu đa chiều và hiện đại (Lâm, 2007). Một số nội dung và kết quả nghiên cứu như sau:

Một là, "Lập bản đồ phân bố của văn hóa Sa Huỳnh; Trong đó, địa vục phân bố của văn hóa Sa Huỳnh được mở rộng theo cả hai chiều Bắc - Nam và Tây - Đông" (Lâm, 2009b, đoạn 3).

Hai là, theo Lâm (2009b),

Xác định được nguồn gốc của văn hóa Sa Huỳnh (theo diễn tiến tiền Sa Huỳnh Sa Huỳnh). Văn hóa Sa Huỳnh giai đoạn Sơ kỳ Sắt được xác định qua những chứng cứ vật thật có nguồn gốc nội sinh từ hợp nguồn của các dòng chảy văn hóa sớm hơn ở giai đoạn cuối thời đại Đá mới đến đầu Kim khí và gọi chung dưới cái tên là tiền Sa Huỳnh. Đáng chú ý, vai trò của các yếu tố ngoại sinh cũng được đánh giá cao trong một số nghiên cứu về cội nguồn của văn hoá Sa Huỳnh (đoạn 4);

Ba là, "Phân loại loại hình trong văn hóa Sa Huỳnh theo không gian và thời gian được rõ ràng hơn. Trong đó, khái niệm văn hoá Sa Huỳnh bao hàm cả thời kỳ tiền Sa Huỳnh và Sa Huỳnh (Vũ, 1991)" (trích trong Lâm, 2009b, đoạn 5);

Bốn là, Nội hàm của "văn hóa Sa Huỳnh buớc đầu được đặt trong bối cảnh" (Lâm, 2009b, đoạn 6) thời đại Kim khí ở Việt Nam và Đông Nam Á;

Năm là, Các nhà khảo cổ học Việt Nam đã nhìn nhận "xem xét lại nhiều quan điểm của các học giả người Pháp về chủ nhân, nguồn gốc và niên đại" (Lâm, 2009b, đoạn 7) của văn hóa $\mathrm{Sa}$ Huỳnh. Sử dụng phương pháp luận duy vật biện chứng và duy vật lịch sử để đánh giá các di tích và di vật. Trong đó, theo Lâm (2009b)

Quá trình diễn tiến của văn hoá Sa Huỳnh đã được đặt trong phổ hệ chung của bối cảnh văn hóa khảo cổ Việt Nam theo mô hình tiến hóa liên tục qua các thời đại khảo cổ, như: Long Thạnh - Bình Châu - Sa Huỳnh (Trung Bộ), song hành 
với Phùng Nguyên - Đồng Đậu - Gò Mun - Đông Sơn (Bắc Bộ) hay Cầu Sắt Bến Đò - Dốc Chùa (Nam Bộ) (đoạn 7).

\subsection{Từ thập niên 90 của thế kỷ $\mathrm{XX}$ - thập niên đầu thế kỷ XXI}

Kế thừa, nhìn nhận lại và phát huy những kết quả nghiên cứu của những giai đoạn trước. Xác định nội hàm thời gian văn hóa Sa Huỳnh thuộc phạm trù sơ kỳ Đồ Sắt - Đồ Sắt phát triển (từ năm 500BC đến thế kỷ I-IIAD). Những địa điểm từ 3,500 2,500BP thuộc giai đoạn Tiền Sa Huỳnh bao gồm các giai đoạn: Long Thạnh - Bình Châu ở địa bàn từ các tỉnh Thừa Thiên Huế - Bình Định và văn hóa Xóm Cồn ở địa bàn các tỉnh từ Phú Yên - Bình Thuận;

Theo Lâm (2009b):

Tư liệu mới đã xóa được nhiều vùng trắng trên bản đồ phân bố của văn hóa Sa Huỳnh. Đặc biệt, các nhà nghiên cứu đã xác định được những trung tâm phát triển của văn hóa Sa Huỳnh giai đoạn sơ kỳ đồ Sắt ở một số lưu vực sông liên quan đến những hình thức tổ chức xã hội hay phân tầng dạng lãnh địa và nhà nước sơ khai (đoạn 9);

"Hình thành một số quan điểm mới về phân loại loại hình văn hóa Sa Huỳnh dưa trên cách tiếp cận sinh thái nhân văn và so sánh văn hóa" (đoạn 10);

"Tăng cuờng hợp tác nghiên cứu giũa các truờng đại học và các viện nghiên cứu trong nước, cũng nhu hợp tác quốc tế trong nghiên cứu văn hóa Sa Huỳnh" (Lâm, 2009b, đoạn 11);

"Khai quật với diện tích rộng nhiều di tích thuộc văn hóa Sa Huỳnh, nhu: cồn Dàng (Thù̀a Thiên Huế), gò Mả Vôi, Lai Nghi (Quảng Nam), gò Quê (Quảng Ngãi), động Cườm (Bình Định) và Hòa Diêm (Khánh Hòa)" (đoạn 12);

"Giải quyết một cách toàn diện và hệ thống hon một số vấn đề của văn hóa Sa Huỳnh, nhu: Nguồn gốc, niên đại, giai đoạn phát triển, mối quan hệ đồng đại, lịch đại, lối sống, và vị trí của văn hóa Sa Huỳnh trong khu vục" (đoạn 13). Bản chất của truyền thống $\mathrm{Sa}$ Huỳnh - Kalanay trong bối cảnh hình thành và phát triển mạng lưới trao đổi kinh tế, văn hóa, và chuyển dịch dân cư ở Đông Nam Á ở những thế kỷ cận kề Công nguyên;

Nghiên cứu theo hướng "tiếp cận những vấn đề kinh tế, xã họi, tinh thần của văn hóa Sa Huỳnh tù quan điểm gần gũi với khảo cổ học mới, nhu: Tiếp cận khảo cổ học kỹ thuật, khảo cổ học mộ táng, hay khảo cổ học xã hội” (đoạn 14);

Sa Huỳnh - Champa là bản chất của sự nối tiếp và biến đổi văn hóa, chính trị, xã hội giữa hai thời kỳ dưới sự tác động của những nguồn lực nội sinh và động lực ngoại sinh trong quá trình ra đời và phát triển. 


\section{VĂN HÓA SA HUỲNH - NHŨ̉NG NHận THỨC QUA PHÁT HIỆN VÀ NGHIÊN CÚU MỚI}

\subsection{Không gian và diễn trình văn hóa Sa Huỳnh}

Về không gian, trước đây Vũ (1991) đã phác thảo các loại hình văn hóa Sa Huỳnh (bao gồm cả thời kỳ Tiền Sa Huỳnh) theo đơn vị hành chính các tỉnh miền Trung. Cách xác định không gian văn hóa là dựa trên những phát hiện và nghiên cứu lúc bấy giờ. Về cơ bản đã giúp chúng ta hình dung về dòng chảy chung của văn hóa này vừa theo lát cắt lịch đại từ sớm đến muộn và vừa theo phân đoạn không gian theo chiều bắc - nam (Hình 1). Trong một số nghiên cứu về diễn biến văn hoá từ Tiền Sa Huỳnh đến Sa Huỳnh đã nhận thấy ít nhất hai truyền thống Long Thạnh - Sa Huỳnh và Bình Châu - Bàu Trám - Sa Huỳnh (Chử, 2004; Vũ, 1996) (Trích trong Lâm, 2009).

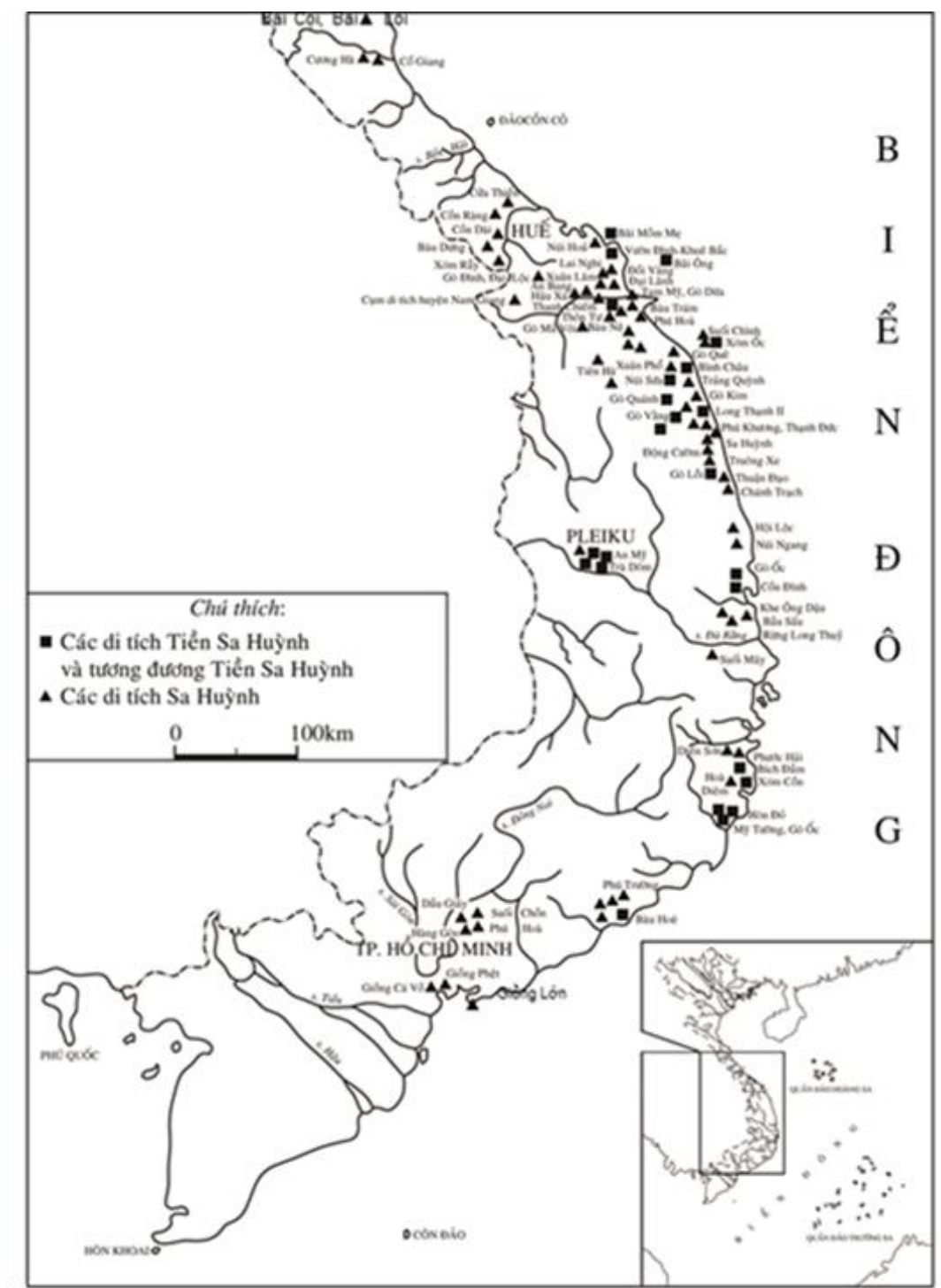

Hình 1. Bản đồ phân bố các di tích Tiền - Sơ sử ở miền Trung Việt Nam

Nguồn: Hán và ctg. (2009). 
Kế thừa những nghiên cứu trước, kết hợp với những phát hiện và nghiên cứu từ những năm 90 của thế kỷ $X X$ đến nay chúng ta đã có thêm những nhận thức mới về tính đa dạng trong thống nhất của văn hóa này. Theo chiều bắc - nam, có thể nhận biết loại hình Sa Huỳnh bắc và Sa Huỳnh nam. Theo chiều tây - đông có thể xác định một cách tương đối loại hình $\mathrm{Sa}$ Huỳnh núi, Sa Huỳnh hạ lưu sông/cửa biển và Sa Huỳnh đảo.

Nguồn tư liệu điền dã của Lâm (2009b) cho thấy:

Truyền thống dùng quan tài gốm và chum hay nồi kéo dài hơn ở khu vực Sa Huỳnh nam so với Sa Huỳnh bắc. Đáng chú ý là hiện tượng cài răng lược của các kiểu quan tài gốm khác nhau trên cùng một địa bàn. Ví như mộ chum là kiểu chum hình trụ, nắp hình nón cụt đặc trưng thì còn song hành cùng là chum hình cầu, mộ đất. Ở Quảng Ngãi có Sa Huỳnh bắc bên cạnh xóm Ốc, suối Chình - Sa Huỳnh nam, trong khi ở Khánh Hoà có Hoà Diêm - Sa Huỳnh nam bên cạnh Diên Khánh, Mỹ Ca - Sa Huỳnh bắc (đoạn 21);

Kết hợp cả hai chiều kích không gian và thời gian, diễn biến của văn hóa Sa Huỳnh có thể được nhóm vào hai truyền thống theo thời gian/loại hình theo không gian như sau (Lâm, 2007; \& Lâm, 2018, tr. 59):

Truyền thống Long Thạnh - Sa Huỳnh (Truyền thống 1): Chum quan tài hình trứng, trụ, cầu lớn, sắt nhiều, đồng hiếm... khởi đầu vào cuối thiên niên kỷ $1 \mathrm{BC}$ và kết thúc cơ bản vào cuối thế kỷ IBC - thuộc Sa Huỳnh bắc (Lâm, 2009b, đoạn 25);

Truyền thống Bàu Trám, Bình Châu, Hoà Vinh II, gò Mã Vôi - Hoà Diêm, Suối Chình... (Truyền thống 2): Chum quan tài hình cầu biến thể, mộ đất nhiều, nhiều hiện vật đồng hơn ở những địa điểm sớm. Táng thức mộ chum tồn tại đến thế kỷ II, IIIAD. Trong truyền thống này có sự tham gia rất mạnh mẽ của các yếu tố từ văn hoá Xóm Cồn, về cơ bản thuộc Sa Huỳnh nam (Lâm, 2009b, đoạn 26);

Về loại hình quan tài gốm và "chum hình tru xuất hiện ở gian đoạn muộn và chấm dưt sự tồn tại vào cuối thế kỷ IBC đến đầu thế kỷ IAD. Chum hình cầu xuất hiện sớm hơn và kéo dài đến nhũng thế kỷ đầu Công nguyên" (Lâm, 2009b, đoạn 26). Diễn trình văn hóa dựa vào loại hình học của chum quan tài, di vật chôn theo và hệ thống niên đại phân tích bằng phương pháp Carbon phóng xạ (C14), AMS (Accelerator Mass Spectrometry) có thể xác định một số giai đoạn phát triển nội tại theo Lâm (2009b) như sau:

Nhóm sớm nhất: Bao gồm những di tích mộ chum với chum quan tài đa dạng về hình thức (hình cầu và hình trứng với nhiều biến thể), được táng thức xen kẽ giữa mộ chum và mộ đất, táng tục hỏa táng (?), cải táng, chôn tượng trưng (?). Đồ gốm tùy táng rất phong phú và đa dạng về loại hình và trang trí cầu kỳ. Điểm nổi bật của những di tích này là sự có mặt của nhiều đồ tùy táng bằng đồng (công cụ và vũ khí) mang dáng dấp của đồ đồng trong văn hoá Đông Sơn ở bắc Việt Nam. Rõ ràng, xu hướng tiếp xúc với văn hoá Đông Sơn là xu thế chính 
trong văn hoá Sa Huỳnh ở giai đoạn sớm. Ở khu vực từ Khánh Hòa đến Ninh Thuận và Bình Thuận những địa điểm văn hóa Sa Huỳnh, như: Phú Trường, Hòa Vinh... có mối quan hệ gần gũi với các di tích đồng đại ở Đông Nam Bộ. Những địa điểm điển hình của nhóm này có các di tích gò Mả Vôi, gò Quê, Bình Châu II, Bình Yên I, Bàu Trám - Trảng Đổng Du, Phú Trường, Hòa Vinh... (đoạn 17);

Nhóm muộn hơn: Gồm những di tích mộ chum thuộc giai đoạn phát triển của văn hoá Sa Huỳnh với loại quan tài gốm chủ đạo là chum hình trụ nhưng có kích thước lớn. Đồ tuỳ táng gồm có công cụ sắt, đồ trang sức bằng thuỷ tinh và mã não. Loại hình mộ đất vẫn còn và tồn tại bên cạnh mộ chum. Trong nhiều địa điểm đã xuất hiện đồ đồng (gương, lục lạc, đồ đựng, và đồ dùng) có nguồn gốc từ Trung Hoa (Hán). Bắt đầu xuất hiện một số loại hình và trang trí trên đồ gốm, kim loại chịu ảnh hưởng của văn hóa Hán như dao sắt có chuôi hình vành khăn kiểu Tây Hán, qua đồng, qua sắt, bát có chân trổ lỗ tam giác kiểu "đậu" ở Động Cườm... Địa điểm tiêu biểu cho giai đoạn này là các di tích An Bang, Hậu Xá, Bình Yên, Gò Dừa, Lai Nghi, Tiên Lãnh, Đại Lãnh, Động Cườm... (đoạn 18);

Nhóm muộn nhất: Là giai đoạn kết thúc của văn hoá Sa Huỳnh và kéo dài tới những thế kỷ sau Công nguyên. Chum mai táng có nhiều loại hình, không chỉ hình trụ mà có khá nhiều chum hình cầu (dạng mộ nồi/vò). Đồ tuỳ táng bằng sắt, bằng đồng. Đồ trang sức bằng mã não, thủy tinh và bằng vàng. Trong bộ đồ tuỳ táng này vẫn tiếp tục phản ánh quan hệ giao lưu văn hoá mạnh mẽ với bên ngoài như Trung Hoa và Ân Độ. Mộ chum, nồi/vò song hành cùng mộ đất và có những khu mộ như vậy ở Quảng Ngãi, Phú Yên, Khánh Hoà, niên đại kéo dài đến thế kỷ II, IIIAD, như: Rừng Long Thủy (Phú Yên), Hoà Diêm (Khánh Hoà), và Suối Chình, Xóm Ốc (Quảng Ngãi). Những di tích này thuộc vào nhóm rất muộn và có thể tính cả nhóm hiện vật sưu tập Hậu Xá II năm 1998. Tại đây, có loại chum trang trí hoa văn in ô vuông kiểu Hán, trang sức hình dấu phẩy, mộ chum trang trí văn in kỷ hà ở Xóm Ốc, mộ đất với bộ đồ đồng thuộc giai đoạn Đông Hán hay bát có bốn chân ở Lai Nghi (đoạn 19).

Về đặc trưng, những di tích thuộc văn hoá Sa Huỳnh được phát hiện ở hầu hết mọi địa bàn từ vùng rừng núi đển các đảo ven bờ (Hình 1$)$. Trong số trên/dưới 100 địa điểm đã phát hiện và nghiên cứu thì, đa số là các khu mộ tang. Mật độ phân bố của các di tích không đồng đều có thể lý giải về mật độ dân số cũng khác nhau. Song, tại các lưu vực sông lớn, số lượng di tích và di vật đã phát hiện ngày càng tăng trong những năm gần đây đã cho thấy những nơi này đã hình thành các không gian sống tương đối lớn, tương đương với lãnh địa quy mô lớn hay liên minh giữa các lãnh địa theo mô hình hình cây hay mô hình những vòng tròn liên kết phổ biến ở Đông Nam Á cùng thời (Hình 2) (đoạn 31).

Có thể nói, cư dân văn hóa Sa Huỳnh sinh sống trên một không gian rộng với địa hình đa dạng. Chính sự đa dạng trong phân bố từ đồng bằng ven sông, ven biển lên vùng núi cao và ra tận ngoài hải đảo trong không gian dọc suốt miền Trung đã tạo cho văn hóa $\mathrm{Sa}$ Huỳnh sự đa dạng sắc thái mang tính địa phương. Qua sự phân bố của các di tích có thể thấy, cư dân Sa Huỳnh đã biết chọn lựa cho mình những vùng đất sinh sống 
khá thuận lợi, dù đó là vùng đồng bằng, vùng núi, hay hải đảo. Các dòng sông luôn là sợi dây gắn kết các di tích lại với nhau, là trục giao thông mà con người có thể di chuyển dễ dàng từ vùng thượng nguồn xuống vùng đồng bằng và ra biển. Sự phân bố của các di tích - phân bố dân cư đã nói lên sự thuận lợi của môi trường sống - nơi đảm bảo cung cấp nguồn sống cho họ. Tùy vào những điều kiện địa lý, môi trường tự nhiên mà họ đã khai thác các thế mạnh của từng vùng sinh thái để sinh sống và hình thành nên các phương thức khai thác kinh tế khá đa dạng trong văn hóa Sa Huỳnh.

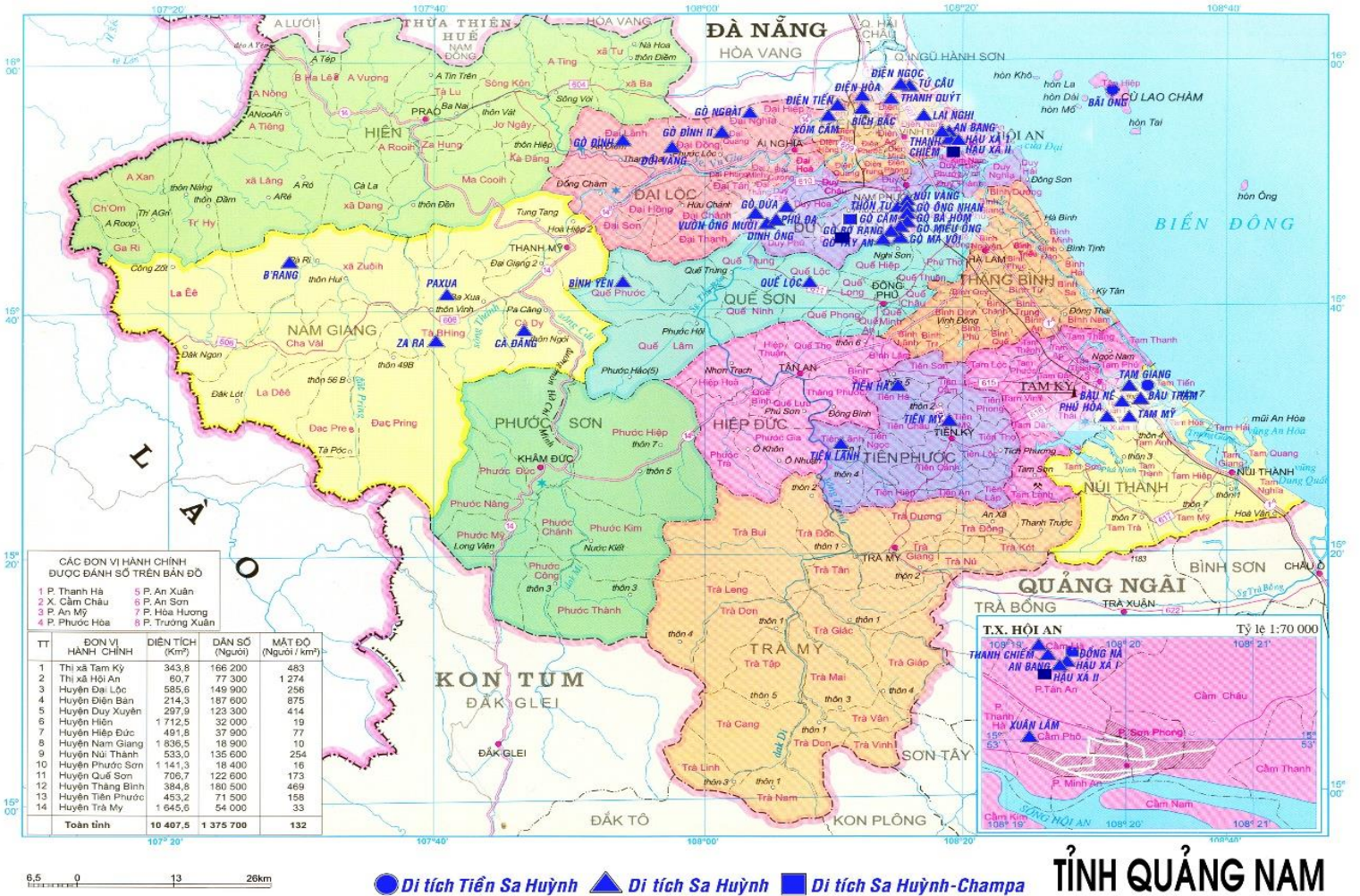

Hình 2. Bản đồ phân bố di tích Tiền - Sơ sử ở lưu vụ̣c và chi lưu của sông Thu Bồn

Nguồn: Lam (2009).

Đại đa số các di tích trong văn hóa Sa Huỳnh được biết đến nay là mộ táng, các dấu vết cư trú phát hiện được rất ít, một số di tích cư trú được nghiên cứu, như: Thôn Tư, Gò Cấm (lớp dưới), Tiên Hà (Gò Miếu), Bàu Nê, (Quảng Nam), Gò Duối, và các di tích Ninh Thân, Ninh Đông, và Diên Điền (Khánh Hòa). Nhóm di tích này đã được phát hiện vào năm 1988, song không có thông báo cụ thể nào nên rất khó để tìm hiểu phương thức cư trú, tổ chức không gian, và mối quan hệ giữa nơi cư trú và nơi chôn người chết. Từ phân bố của nhóm di tích trên cồn cát ven sông, như: Bà Rén, Thôn Tư, gò Mả Vôi, và gò Miếu Ông ở Duy Trung, Duy Xuyên (Quảng Nam) thì có thể lý giải làng cư trú của cư dân cổ thường ở " $k h u$ vục gần dòng chảy, thấp hơn so với nơi chôn cất, tầng văn hoá không dày, dễ bị bào mòn và làm xáo trộn. Trong khi đó, với đặc tính của các dòng sông Miền Trung là ngắn, độ dốc lớn" (Lâm, 2009c, đoạn 24) kết hợp với "nhũng cơn lũ miền núi đột ngột và hung dũ, gây nhũng hiện tuợng lở bò̀, đất đồ và đất truợt" (Lê, 1998, tr. 192). Nhiều khả năng, "nhiều di tích cu trú đã bị lở xuống sông và mất hết dấu 
tích - đây là hiện tuợng đến nay vẫn xảy ra" (Lâm, 2009c, đoạn 24). Vì vậy, nơi cư trú của người $\mathrm{Sa}$ Huỳnh cổ rất ít khi được phát hiện.

Như vậy, theo Lâm (2009c),

Trong văn hóa Sa Huỳnh quy mô và phạm vi phân bố của những cộng đồng dân cư mở rộng hơn rất nhiều so với thời kỳ tiền $S a$ Huỳnh đã cho thấy sự tăng nhanh và mở rộng mức độ khai thác các nguồn lợi từ tự nhiên. Trong xã hội, do sự gia tăng của đồ sắt cũng dẫn đến sự tích luỹ của cải vật chất và đẩy mạnh tính phức hợp của xã hội. Quy mô những khu mộ táng và sự phân tầng của các mức mộ táng, hay đồ tùy táng gia tăng theo thời gian từ sớm đến muộn cũng nói lên điều đó (đoạn 76).

\subsection{Các đặc trưng văn hóa}

\subsubsection{Văn hóa vật chất}

Văn hóa vật chất của các cộng đồng cư dân cổ chủ yếu được diễn giải từ những di tích và di vật xuất lộ nên còn khá nhiều khoảng trống chưa thể lấp đầy chứng cứ trực tiếp. Tuy nhiên, khi áp dụng các lý thuyết và phương pháp của khảo cổ học thương mại, khảo cổ học mộ táng hay khảo cổ học xã hội, chúng ta có thể khái quát một số đặc trưng văn hóa vật chất:

- Các ngành nghề thủ công phát triển với một số ngành có quy mô sản xuất lớn và mang tính chuyên hoá ở mức độ nhất định nhu sản xuất đồ gốm, luyện kim sắt, chế tạo đồ trang súc bằng đá và thủy tinh" (Lâm, 2009c, đoạn 77): Trước hết, nghề làm gốm cũng như nhiều cư dân sơ kỳ Đồ sắt đã đóng vai trò đáng kể cả ở khía cạnh thực tế và khía cạnh tinh thần. Tuy vậy, nghề làm gốm chúng ta chỉ có thể dựa vào những sản phẩm đã qua sử dụng còn lưu lại trong các khu mộ táng hay nơi cư trú. Đến nay, có rất ít tài liệu thực địa cho biết về nơi sản xuất hay nơi khai thác nguyên liệu để làm gốm của người Sa Huỳnh.

- Nhìn chung, đồ gốm trong văn hoá Sa Huỳnh phần lớn được tìm thấy trong các khu mộ. Vì vậy, về loại hình, chất liệu, hoa văn trang trí và cả kỹ thuật chế tác liên quan chặt chẽ tới sự biến đổi theo nhu cầu sử dụng trong táng thức (Hình 3). Gốm ở các địa điểm cư trú không khác biệt so với gốm trong mộ táng, song đơn giản hơn rất nhiều về loại hình. Giữa hai loại hình theo khu vực Bắc và Nam của văn hoá Sa Huỳnh bên cạnh những nét chung thì đồ gốm cũng có những đặc trưng riêng (Hoàng, 2008; Lâm, 2008) (Trích trong Lâm, 2009b, đoạn 35).

Đối với tổ hợp gốm Sa Huỳnh bắc, các mộ quan tài gốm hầu hết là dạng chum hình trụ hoặc hình trứng, nắp hình nón cụt. Ngoài ra, cũng có một số quan tài dạng nồi/vò. Kiểu chum hình trụ chiếm tỷ lệ lớn, có khá nhiều biển thể khác nhau và có mặt trong hầu hết các địa điểm của văn hóa Sa Huỳnh. Kiểu chum hình trứng, xuất hiện từ giai đoạn Long Thạnh, chum có những biến thể khác nhau và được tìm thấy trong một 
số địa điểm như cồn Ràng, gò Mả Vôi, gò Miếu Ông, Hậu Xá, và Thạch Bích. Kiểu chum thứ ba là dạng nồi/vò, kích thước nhỏ, hình dáng giống như những chiếc nồi/vò. Nhìn chung, hình dáng quan tài dạng hình trụ và hình trứng có nắp hình nón cụt rất quy chuẩn, kích cỡ và kiểu dáng thống nhất giữa các địa điểm trong một không gian rộng. Đồ gốm tuỳ táng có các loại, như: Nồi, bình, bát, bát/mâm bồng, cốc, chén... Đồ trang sức, có: Khuyên tai ba mấu, khuyên tai con đỉa, hạt chuỗi, công cụ sản xuất (dọi xe chỉ) và đồ minh khí (chủ yếu là nồi). Chiếm số lượng lớn nhất trong tất cả là các loại nồi, phổ biến nhất với hai kiểu dáng chính là nồi miệng loe không có chân đế, thân cong tròn hoặc có gờ gãy góc ngang thân. Các kiểu bình hình con tiện, bình vai xuôi dài có gờ gãy góc thấp gần đáy có những mô típ hoa văn khắc vạch in chấm, khắc vạch tạo các nhóm đường thẳng, tam giác kết hợp tô màu là điển hình của loại hình $\mathrm{Sa}$ Huỳnh bắc. Kiểu mâm bồng có kích thước lớn, vành miệng tạo gờ gãy góc với thân, thân khum vát, chân đế cao cũng chỉ có ở địa bàn của vùng Trung Trung Bộ. Hiện vật đặc trưng nhất của loại hình gốm Sa Huỳnh bắc là đèn gốm, loại hình hiện vật này thường được trang trí rất cầu kỳ, kết hợp giữa các mô típ khắc vạch và tô màu đỏ. Cùng với đèn gốm, các đồ gốm khác như hạt chuỗi và khuyên tai hình con đỉa, khuyên tai ba mấu bằng gốm cũng mới chỉ tìm thấy trong loại hình Sa Huỳnh bắc.

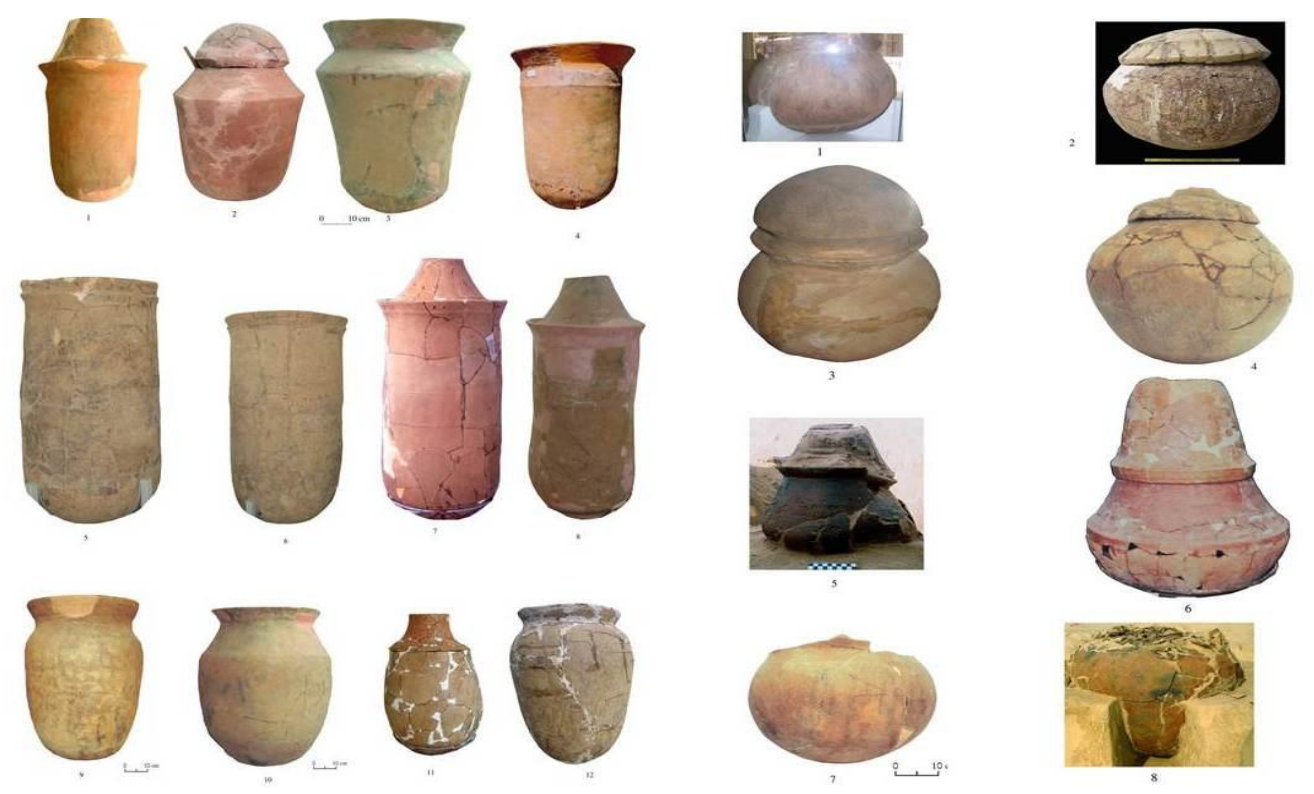

Hình 3. Các loại chum quan tài trong văn hóa Sa Huỳnh

Nguồn: Hoàng (2015).

Đối với tổ hợp gốm Sa Huỳnh nam, chum quan tài đa dạng về loại hình nhưng không giống với Sa Huỳnh bắc. Loại chum hình cầu ở Sa Huỳnh nam giống chum ở Giồng Cá Vồ hơn. Đồ gốm tùy táng đa dạng nhưng không có loại đèn như Sa Huỳnh bắc. Trong di tích Hoà Diêm, một số mộ chum có niên đại từ sau Công nguyên có nhiều nét tương đồng với dòng gốm Kalanay. Nhìn chung, đồ gốm Sa Huỳnh nam có những nét kế thừa từ gốm Xóm Cồn, hoa văn chải chiếm tỉ lệ lớn, văn in mép sò, in chấm thành các đồ án không kèm văn khắc vạch tạo biên rất nhiều, trong khi hoa văn tô màu không phổ biến. 
Nhìn chung, gốm của hai loại hình Sa Huỳnh bắc và nam "được trang trí đẹp với những đồ án hoa văn đa dạng. Hoa văn khắc vạch kết hợp tô màu, những đồ án và phong cách trang trí từ giai đoạn tiền Sa Huỳnh tiếp tục tồn tại và phát triển trong giai đoạn này" (Lâm, 2013, đoạn 182). Đặc biệt là hoa văn in mép sò độc lập hay in mép sò kết hợp với khắc vạch, miết láng tạo thành những băng trang trí có giá trị mỹ thuật cao. Đáng chú ý là loại gốm tô màu đen (tô ánh chì) "và đỏ thành tù̀ng băng uốn lượn hay góc cạn, xen lẫn nhũng băng bên trong trang trí nhũng đường vạch nhỏ, chấm dải, in mép sò... trở thành phuơng pháp trang trí phổ biến" (Lâm, 2013, đoạn 182) của văn hóa Sa Huỳnh. Với loại văn thừng, có lẽ loại văn này chỉ "đóng vai trò kỹ thuật hơn là trang trí, kiểu loại văn thù̀ng giai đoạn này đơn giản hơn so với giai đoạn sớm" (Lâm, 2013, đoạn 182). Tất cả gốm Sa Huỳnh đều là gốm thô, đất sét pha cát, đá hay vỏ nhuyễn thể... Kỹ thuật tạo dáng khá đồng nhất của người thợ gốm. Quy trình chế tác gồm các khâu tạo dáng cơ bản và tu chỉnh. Đối với các loại gốm lớn như các loại chum gốm, họ sử dụng kỹ thuật dải cuộn kết hợp bàn đập, hòn kê. Đối với các đồ gốm gia dụng, họ cũng dùng kỹ thuật dải cuộn, ấn tay, nặn nguyên khối kết hợp với ghép nổi con chạch. Sau khi tạo dáng, gốm được cạo sửa lại và dấu vết này để lại trên gốm Sa Huỳnh khá phổ biến. Chân đế hoặc vành miệng trong của đèn gốm sẽ được ghép sau khi bề mặt gốm hơi se lại. Bước cuối cùng là tạo hoa văn, các hoa văn trang trí được làm bằng kỹ thuật in, tô màu, và khắc vạch (Lâm, 2007).

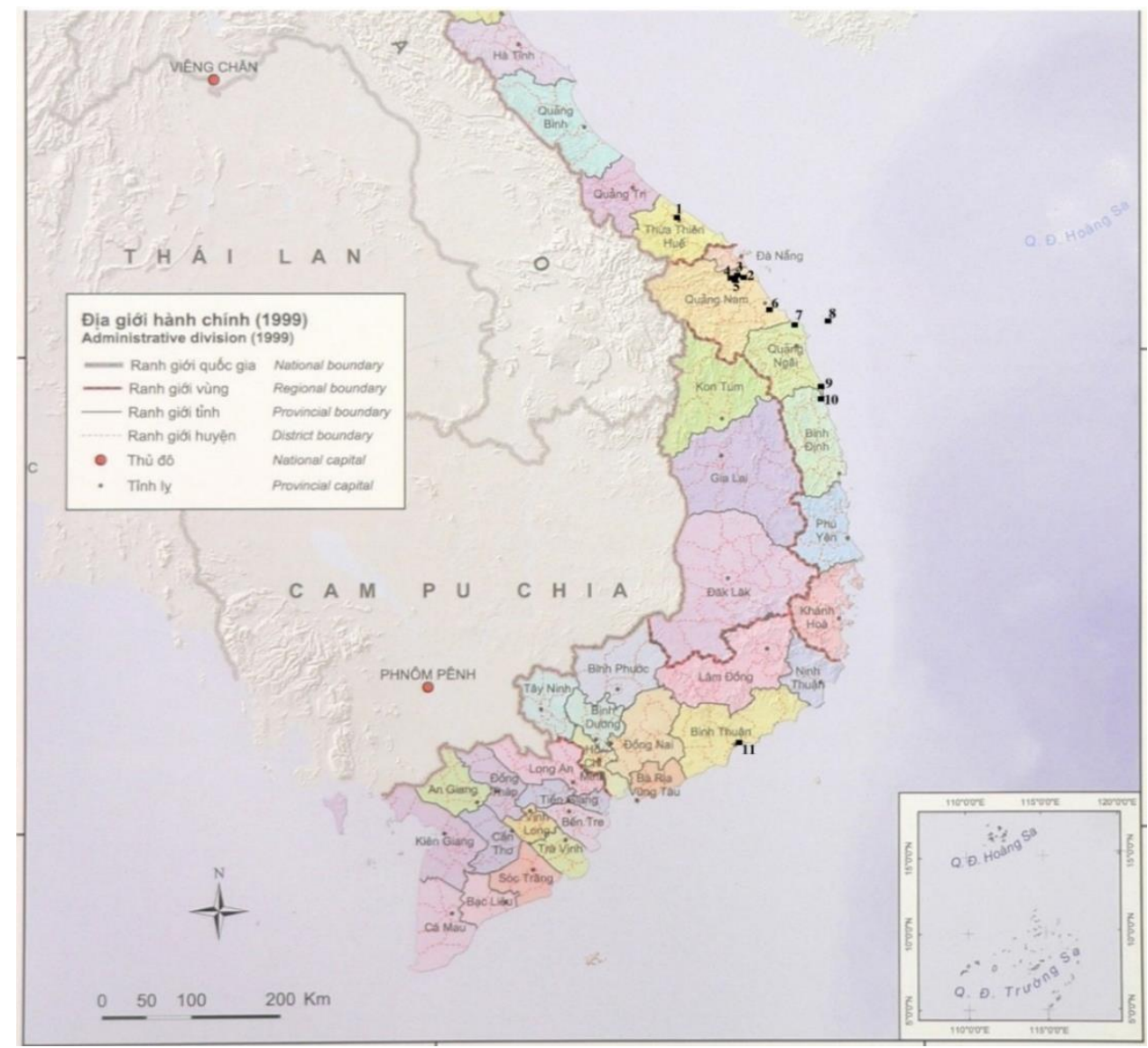

Hình 4. Bản đồ phân bố các trung tâm sản xuất gốm Sa Huỳnh

Nguồn: Hoàng (2015). 
Về kỹ thuật nung, dựa trên những tư liệu phân tích mà Hoàng (2008) cho rằng người Sa Huỳnh đã nung gốm ngoài trời, nhiệt độ nung khoảng $600-900^{\circ} \mathrm{C}$. Dựa vào phân tích loại hình và kỹ thuật có thể xác định được 11 khu vực sản xuất gốm trong không gian văn hoá Sa Huỳnh từ Huế đến Bình Thuận (Hình 4). Những tư liệu gần đây còn cho biết khu vực Bãi Cọi ở Hà Tĩnh cũng là một nơi sản xuất gốm. Về cơ bản, đồ gốm ở đây mang những nét đặc trưng của gốm Sa Huỳnh về chất liệu, loại hình và kỹ thuật chế tác ảnh hưởng đậm nét từ gốm thuộc văn hóa Đông Sơn (Hoàng, 2015).

Đồ sắt là loại hình di vật nổi bật nhất trong văn hoá Sa Huỳnh. Trong đó, bộ công cụ và vũ khí bằng sắt hết sức đa dạng. Tại những địa điểm văn hoá Sa Huỳnh, công cụ sắt chiếm số lượng lớn. Đồ sắt được sản xuất chủ yếu bằng phương pháp rèn, kết quả phân tích chín mẫu của sưu tập đồ sắt Đại Lãnh đã cho thấy chúng đều được chế tạo bằng phương pháp rèn, kỹ thuật đúc cũng gặp ở một số hiện vật. Nhìn chung, những người thợ sắt cố $\mathrm{Sa}$ Huỳnh có tay nghề khá thành thạo trong việc rèn nóng. Số lượng đồ sắt Sa Huỳnh phát hiện được đến nay "đã lên tới hàng trăm chiếc" (Lâm, 2013, đoạn 180). Chủng loại đồ sắt khá "đa dạng gồm rựa, dao quắm, giáo, mai, liềm, thuổng, kiếm ngắn, dao, qua đồng...” (Lâm, 2013, đoạn 180). Theo Lâm (2013), có thể nói,

Đồ sắt trong văn hóa Sa Huỳnh nếu đặt trong tương quan với các trung tâm văn hoá Đông Sơn ở phía Bắc, văn hoá Dốc Chùa ở phía Nam thì số lượng và sự phổ biến rộng rãi của đồ sắt trong văn hoá $\mathrm{Sa}$ Huỳnh nhiều hơn hẳn. Trong bộ sưu tập hiện vật sắt, đặc trưngt chủ đạo là tính thống nhất về loại hình và kỹ thuật dù được phát hiện trong/tại nhiều địa điểm mang tính địa phương hay khu vực rõ nét. Đồ sắt đã đóng vai trò thống nhất và kết tinh văn hoá ở Miền Trung Việt Nam thời đại Sơ sử. (đoạn 180).

Đến nay, nguồn gốc của nghề luyện kim sắt trong văn hóa Sa Huỳnh vẫn chưa được nghiên cứu đầy đủ, "trong một số địa điểm đã tìm thấy dấu tích của rèn sắt và luyện gang tại chô̂, nhu ở Đại Lãnh (Đại Lộc, Quảng Nam)" (Lâm, 2013, đoạn 180) nhưng cần có những nghiên cứu thêm. Tại địa điểm Gò Quê, trong chum mộ số 1 (hố khai quật 3 ) đã tìm thấy khoảng 50 cục quặng sắt. Các nhà khai quật lý giải đây là hiện tượng thu gom nguyên liệu để chế tác đồ sắt tại chỗ, hay ở Động Cườm (Bình Định) và Diên Sơn (Khánh Hoà) quặng sắt cũng được chôn trong mộ chum. "Có thể, luyện kim sắt trong văn hoá Sa Huỳnh có mối quan hệ chặt chẽ với khu vục Đông Nam Á lục địa" (Lâm, 2013, đoạn 180) và hải đảo. Giai đoạn cuối của nền văn hoá này, "loại hình công cu và vũ khí bằng sắt thể hiện sư giao luu văn hoá với người Hán (Trung Hoa) qua các loại hình nhu mũi nhọn, qua, dao có chuôi hình vành khăn kiểu Tây Hán" (Lâm, 2013, đoạn 180). Với đồ sắt tìm thấy trong một số địa điểm ở địa bàn nam Sa Huỳnh lại cho thấy nhiều nét tương đồng với đồ sắt Đông Nam Á hải đảo. Đồ đồng trong văn hóa $\mathrm{Sa}$ Huỳnh "so với đồ sắt thì it hơn nhiều về số luợng. Trong một vài năm gần đây, trong các khu mộ táng" (Lâm, 2013, đoạn 181) ở Gò Mả Vôi, gò Quê, gò Dừa, Lai Nghi... "đã tìm thấy nhiều đồ đồng tùy táng, nhu công cu, vũ khí, đồ nghi lê̂... Nhiều đồ đồng được phát hiện trong cả mộ chum và mộ đất" (Lâm, 2013, đoạn 180). Phần lớn đồ đồng tùy táng là sản phẩm của trao đổi với văn hoá Đông Sơn, như: Trống đồng, công cụ, và vũ khí; Với văn hoá Đồng Nai như: Rìu có lưỡi cong hình Parabola; Với văn hoá Hán (Trung Hoa) như: Bát, đĩa, bình, ấm, gương... Tất nhiên, không loại trừ người Sa 
Huỳnh tự sản xuất tại chỗ - tuy chứng cứ còn quá ít. Những dấu vết liên quan đến nghề đúc đồng đã được tìm thấy nhưng ở giai đoạn sớm hơn như ở địa điểm Bình Châu hay Bàu Trám. Một vài khuôn đúc bằng đá (đúc rìu kiểu Dốc Chùa) được tìm thấy ngẫu nhiên ở Khánh Hoà và Ninh Thuận... hay dấu tích của những mảnh nồi nấu đồng, gî, xỉ, giọt đồng cũng đã được tìm thấy ở địa điểm cư trú Thôn Tư (Quảng Nam). Tuy vậy, dấu ấn giao lưu trao đổi kiểu như đồ đồng tìm thấy trong các di tích mộ chum vùng nam Trung Bộ (Phú Yên, Khánh Hòa...) có mối quan hệ chặt chẽ với văn hóa Đồng Nai. Nhưng, không thể phủ nhận, nghề luyện kim ra đời và phát triển đã đóng vai trò quan trọng trong văn hoá Sa Huỳnh. Đặc biệt, nghề luyện/rèn sắt là vượt trội và đồ sắt đã tác động mạnh mẽ tới những khía cạnh đời sống vật chất của cư dân Sa Huỳnh.

Nghề chế tác đồ trang sức bằng đá và thủy tinh cũng là nghề thủ công quan trọng của người Sa Huỳnh. Cư dân cổ Sa Huỳnh "có năng khiếu, khéo tay, và mỹ cảm cao; Ho va thích dùng đồ trang sức (vòng, nhẫn, khuyên tai, vật đeo hình dấu phảy, hạt chuỗi...) bằng thuỷ tinh, mã não, đá quý, đá hay đất nung” (Lâm, 2013, đoạn 183). Khuyên tai (hay bùa đeo) hai đầu thú và ba mấu là một trong những đồ trang sức đặc sắc của người Sa Huỳnh (Hình 5). Địa bàn phân bố của khuyên tai ba mấu là hầu khắp các địa điểm thuộc văn hóa $\mathrm{Sa}$ Huỳnh. Nhưng, với loại hai đầu thú cho tới nay chỉ được phát hiện ở một số vùng. Ngoài ra, trong các địa điểm thuộc giai đoạn muộn đã tìm thấy hạt chuỗi hình con vật như hổ, chim nước và loại hạt chuỗi mã não... Hạt chuỗi, khuyên tai bằng vàng hay hạt chuỗi thủy tinh mạ vàng cũng đã được người Sa Huỳnh sử dụng và chôn theo mộ táng - với những loại trang sức này thường được xác định là nhập từ bên ngoài. Trong di tích Đại Lộc (Quảng Nam) hay Giồng Cá Vồ (TP. Hồ Chí Minh) đã phát hiện nhiều khuyên tai hai đầu thú ở dạng chế tác dở. Trong văn hóa Đông Sơn hay các địa điểm ở Philippines, Thái Lan... cũng đã phát hiện loại khuyên tai hai đầu thú đây là những bằng chứng về sự lan toả ảnh hưởng của văn hoá Sa Huỳnh sang các văn hóa đồng đại.

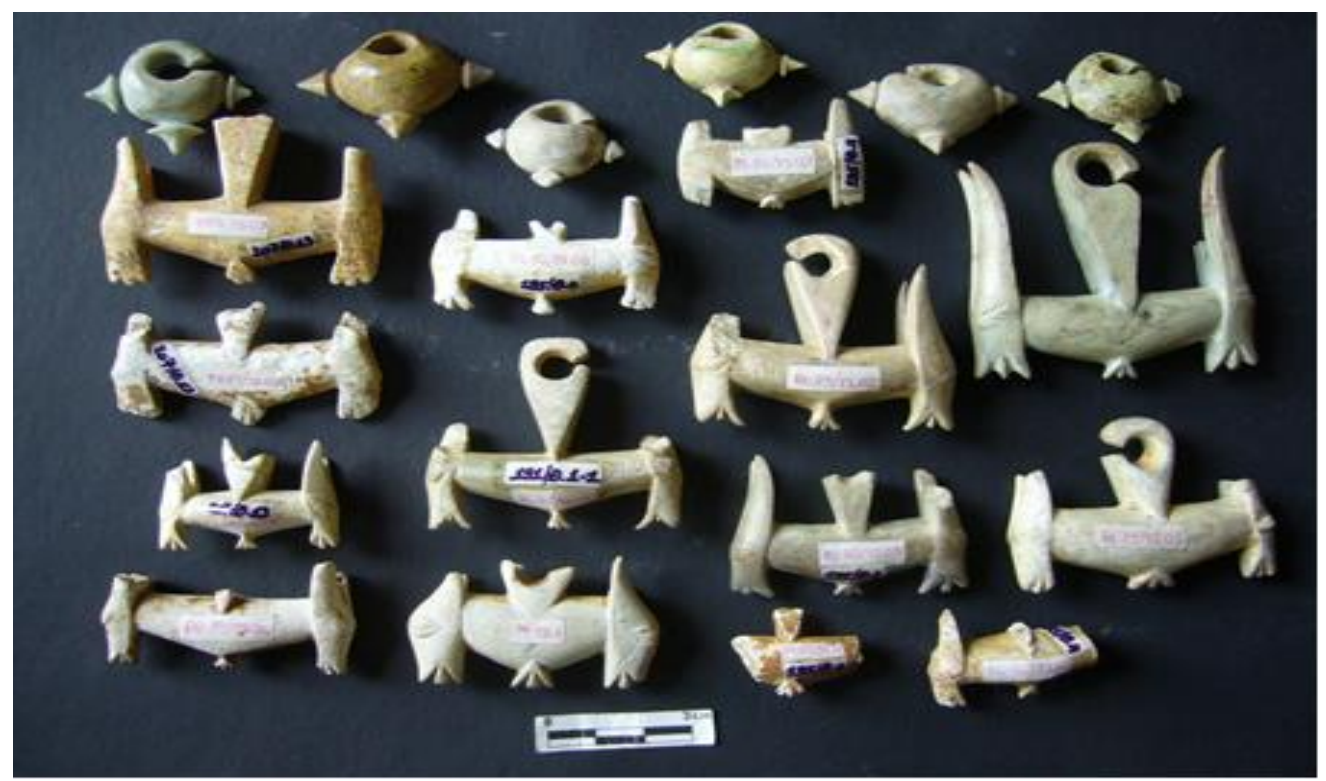

Hình 5. Hai loại hình khuyên tai đặc trưng của văn hoá Sa Huỳnh

Nguồn: Nguyễn (2017). 
Nhìn chung, hai loại khuyên tai này cùng với những biến thể của chúng được phát hiện ở Philippin, Campuchia, Thái Lan... là hàng hoá mậu dịch của Đông Nam Á lúc bấy giờ. Những nghiên cứu của Nguyễn (2017) đưa ra khá nhiều vấn đề liên quan đến việc chế tạo và phân bố của những loại khuyên tai đặc trưng Sa Huỳnh. Đó là, những khuyên tai phát hiện được ở Đông Nam Á được làm bằng nguyên liệu từ Đài Loan, trong khi tại địa bàn Sa Huỳnh, nguyên liệu Đài Loan chỉ chiếm tỉ lệ nhỏ, nguyên liệu từ nhiều nguồn gốc chiếm tỉ lệ lớn. Khuyên tai - hàng mậu dịch ở Đông Nam Á kiểu loại đơn giản hơn rất nhiều so với loại nội địa Sa Huỳnh. Một vấn đề khác cũng cho thấy, đồ gốm hay đồ trang sức của văn hoá Sa Huỳnh có rất nhiều nét chung với các văn hoá khác cùng thời ở Đông Nam Á - đặc biệt là với Đông Nam Á hải đảo. Điều này lý giải đó là kết quả của mạng lưới trao đổi nguyên liệu và sản phẩm. Đáng chú ý là sự xuất hiện của một số trung tâm sản xuất trong khu vực Đông Nam Á.

Đồ trang sức bằng thuỷ tinh rất phổ biến trong văn hoá Sa Huỳnh muộn, như: Khuyên tai, vòng tay, hạt chuỗi các loại... Đến nay, còn nhiều ý kiến khác nhau về nguồn gốc đồ thuỷ tinh trong văn hoá Sa Huỳnh, "nhung theo đa số các nghiên cứu thì thuỷ tinh Sa Huỳnh phần lớn được chế tác tại chồ" (Lâm, 2009b, đoạn 41). Có thể nói, người Sa Huỳnh "có nghề thủ công chế tạo thuỷ tinh phát triển, một số sản phẩm được buôn bán trao đổi đi nhũng nơ khác trong khu vực Đông Nam Á" (Lâm, 2009b, đoạn 41). Theo Lâm (2009b),

Chính sự thống nhất trong loại hình và mức độ tinh tế của kỹ thuật đã cho thấy có những người thợ chuyên chế tác mặt hàng thuỷ tinh và ở mức độ nào đó họ đã biết cập nhật trình độ sản xuất thuỷ tinh của khu vực (Lâm, 2007). Tuy vậy, quy mô sản xuất chắc vẫn dừng ở hộ gia đình hay cá nhân, cho đến nay chưa có những chứng cứ về sự tồn tại của trung tâm chế tác đồ thuỷ tinh. Chứng cứ thuyết phục nhất về nghề chế tạo thủy tinh được ghi nhận trong di tích Giồng Cá Vồ (TP. Hồ Chí Minh). Bên cạnh sử dụng đồ thuỷ tinh bản địa thì họ vẫn nhập đồ trang sức thuỷ tinh nấu chảy lại của Ân Độ (Francis, 2004, tr. 2) (Trích trong Lâm, 2009b, đoạn 41);

Phuoong thức mư sinh "đa dạng và linh hoạt trong sinh kế tận dụng tối đa ưu thế địa hình và môi truờng sinh thái" (Lâm, 2009b, đoạn 33): Dựa vào những dấu tích khảo cổ học và dữ liệu môi trường sinh thái và so sánh dân tộc học có thế thấy các cộng đồng cư dân văn hoá Sa Huỳnh có cơ cấu kinh tế đa dạng, như: Kết hợp giữa kinh tế sản xuất, kinh tế khai thác, sản xuất thủ công và trao đổi buôn bán. Như trên đã đề cập, môi trường sống của người Sa Huỳnh rất đa dạng cả về địa hình, địa mạo, khí hậu, đất đai... mặc dù yếu tố biển có vai trò quan trọng nhưng tác động của biển đối với cư dân là khác nhau giữa Sa Huỳnh bắc, Sa Huỳnh nam, Sa Huỳnh núi, Sa Huỳnh hạ lưu sông, Sa Huỳnh đảo...

Đến nay, nghề trồng trọt nói chung, và trồng lúa nói riêng chúng ta cũng chưa có thật nhiều bằng chứng. Tuy vậy, một số dẫn liệu "về vỏ trấu trong dồ gốm, gạo cháy trong mộ chum ở Lai Nghi, Tiên Phước, gò Miếu Ông...; Hay loại hình nông cu bằng sắt, bằng đồng đã thống kê được thì đồ sắt thuộc nhóm công cu sản xuất chiếm số luoọng rất lớn so với vũ khí - 306 công cu sản xuất/ 56 vũ khí)" (Lâm, 2009b, đoạn 33) đã lý 
giải cho vai trò nhất định của trồng trọt trong đời sống cư dân. Lúa có lẽ được trồng ở các loại thổ nhưỡng khác nhau, tạo ra các giống lúa khác nhau. Các tài liệu về khảo cổ học và dân tộc học cho biết, ở miền Trung là nơi có nhiều giống lúa phù hợp với cả môi trường nắng nóng, khô và nắng nóng cùng bão lũ. Một số giống cây ăn quả nhiệt đới mà sau này chúng ta biết trong sử liệu viết về Champa có lẽ có nguồn gốc từ thời $\mathrm{Sa}$ Huỳnh.

Miền Trung Việt Nam với sự giàu có và phong phú sản vật liên quan đến núi rừng sông, biển, và đặc biệt là nguồn lâm thổ sản hải sản rất đa dạng đã được cư dân $\mathrm{Sa}$ Huỳnh khai thác hiệu quả, sự hiện diện của các cộng đồng lớn ở vùng núi Trường Sơn, thượng nguồn các sông mà dấu vết còn lại là các khu mộ táng ở miền núi Quảng Nam hay Quảng Ngãi có thể lý giải như là kết quả của việc khai thác và trao đổi sản vật thượng nguồn, hạ nguồn sôi động trong thời sơ sử.

Các ngành nghề thủ công rất phát triển, thúc đẩy buôn bán và trao đổi bên trong, cũng như bên ngoài. Như trên đã bàn về các loại hình di vật, một số nghề thủ công sản xuất có lẽ đã vượt quy mô gia đình và đạt quy mô làng. Trong đó, nghề chế tác đồ kim loại cho thấy có sự hiện diện của thợ cả lành nghề, chế tác đồ gốm đã được chuyên hoá ở mức độ nào đấy để sản xuất những mặt hàng có tính chất biểu trưng cao trong nghi lễ, trong tang lễ và trang trí. Theo Lâm (2009b), có thể nói:

Văn hoá Sa Huỳnh là sản phẩm của những cư dân có cuộc sống định cư trên đất liền nhưng với xu hướng hướng biển mạnh mẽ. Hệ sinh thái chủ đạo tạo nên nhiều đăc trưng văn hoá là hệ sinh thái cồn và bàu. Người cổ Sa Huỳnh có nền kinh tế đa ngành kết hợp giữa trồng lúa nước ở các đồng bằng nhỏ duyên hải, trồng lúa kiểu nương rẫy ở vùng đồi gò. Cư dân văn hoá Sa Huỳnh sớm biết khai thác những nguồn lợi của biển, của rừng, biết phát triển các nghề thủ công, từng bước họ đã mở rộng quan hệ trao đổi buôn bán với các cư dân trong khu vực Đông Nam Á lục địa, hải đảo và rộng hơn nữa là với Ấn Độ và Trung Hoa (đoạn 34).

Mở rộng và phức hợp hoá mạng luới trao đổi trong và ngoài: Với nhu cầu sự tăng mạnh trong tiêu thụ của sản phẩm làm ra của các cộng đồng cư dân kéo theo sự mở rộng và phức tạp hoá mạng lưới trao đổi trong và ngoài. Chính sự phát triển ngày càng nhanh và mạnh mang tính phức hợp của xã hội là nguyên nhân chính quan trọng dẫn đến sự có mặt của nhiều hàng hoá có nguồn gốc từ bên ngoài. Kết quả khai quật cho thấy một số ngôi mộ chứa hiện vật có nguồn gốc từ Trung Hoa, Ấn Độ, miền Bắc Việt Nam... phân bố ở nhiều dạng địa hình khác nhau ở cả địa bàn Bắc và Nam của văn hoá Sa Huỳnh. Chính những di vật mang tính biểu thị địa vị, thân phận đã góp phần thúc đẩy phân tầng xã hội trong từng lãnh địa và đặc biệt là sự phân hoá giữa các lãnh địa. Hiện vật nhập khẩu và cùng với chúng là những ý tưởng văn hoá - kỹ thuật đã góp phần tạo ra một số chuyển biến cơ cấu giữa các ngành thủ công và trong mỗi ngành. Tất cả những điều này đã tạo ra những thay đổi trong khai thác tìm kiếm nguyên liệu, tổ chức sản xuất và cách thức phân phối sản phẩm (thiết yếu và xa xỉ) trong từng lãnh địa và giữa các lãnh địa (đoạn 42 ). 
Văn hóa Sa Huỳnh có mối quan hệ giao lưu rất mạnh mẽ với các văn hóa đồng đại trong khu vực. Đến giai đoạn cuối của nền văn hóa Sa Huỳnh (thế kỷ IIBC thế kỷ IAD) đã có thêm sự tiếp xúc và trao đổi với những vùng xa hơn như Trung Hoa, Ân Độ, Địa Trung Hải... Ngoài ra những di vật khảo cổ học liên quan đến sự tiếp xúc giữa Miền Trung Việt Nam với thế giới bên ngoài như với Đông Nam Á, Hải đảo, Trung Hoa, Ân Độ, Địa Trung Hải ngày càng được phát lộ nhiều trong các di tích Sa Huỳnh ở Quảng Nam, Quảng Ngãi, Bình Định, Khánh Hoà... Những tiếp xúc và trao đổi giữa Sa Huỳnh - Hán, Sa Huỳnh - Ân bắt đầu từ giai đoạn giữa của văn hóa Sa Huỳnh (từ thế kỷ IVBC) rồi tăng cường trong giai đoạn cuối và tăng mạnh mẽ từ thế kỷ I, II trước và sau Công nguyên. Chứng cứ về sự tiếp xúc và ảnh hưởng này thường tìm thấy ở địa điểm hay nhóm địa điểm phân bố ven sông lớn, cửa sông ven biển, những địa hình thuận tiện cho việc tiếp xúc và trao đổi kinh tế văn hóa. Có thể thấy rằng, mạng lưới trao đổi và buôn bán nội vùng và liên vùng cùng với buôn bán khoảng cách xa có một vai trò quyết định trong việc tiếp thu, chuyển tiếp và biến đổi những yếu tố văn hoá ngoại sinh trong văn hoá Sa Huỳnh để dẫn đến những thay đổi quan trọng trong quá trình tiến hoá nội tại và thay đổi cấu trúc, quan hệ xã hội (đoạn 42).

\subsubsection{Văn hóa tinh thần}

Đời sống tinh thần của cư dân Sa Huỳnh chủ yếu được biết đến thông qua những táng thức, táng tục và loại hình, chất lượng của đồ chôn theo - do tư liệu liên quan đến cư trú khá hiếm. Cư dân văn hóa Sa Huỳnh chủ yếu dùng chum vò gốm lớn làm quan tài, chủ yếu chôn thẳng đứng ${ }^{2}$ bất kể táng thức hoả táng, cải táng, chôn một lần, chôn tượng trưng, chôn đơn hay kết hợp nhiều người, nhiều kiểu táng. Đối với trẻ em thường chôn một lần, chưa rõ có hay không tục cải táng ${ }^{3}$. Có chum đơn và chum lồng (dạng trong quan, ngoài quách) chôn thành từng cụm, thẳng hàng hoặc ô bàn cờ. Mộ đất ngày càng được nhận diện nhiều hơn trong văn hoá $\mathrm{Sa}$ Huỳnh và có mặt cả ở loại hình $\mathrm{Sa}$ Huỳnh bắc, Sa Huỳnh nam và Hải đảo. Mặc dù số lượng ít hơn so với loại hình mộ chum nồi, nhưng mộ đất cũng có các tục như hoả táng, hung táng, cải táng, và chôn tượng trưng. Mộ đất thường được cho là do có ảnh hưởng từ văn hóa Đông Sơn, đặc biệt là tî̉ lệ mộ đất ở những địa điểm gò Quê hay gò Mả Vôi nơi có nhiều đồ đồng Đông Sơn. Tuy nhiên vấn đề này cũng cần nghiên cứu thêm, ngay trong văn hoá tiền $\mathrm{Sa}$ Huỳnh, kiểu chôn mộ đất cũng đã được cư dân thực hành. Tài liệu khảo cổ học ngày càng cho thấy trong một nền văn hoá khảo cổ, một giai đoạn khảo cổ có thể có nhiều cách thức mà con người sử dụng chôn cất người chết vừa đảm bảo tính vệ sinh môi trường, vừa tỏ lòng thương tiếc, thương nhớ, lưu giữ kỷ niệm, và vừa thoả mãn nhu cầu thể diện, thể hiện cũng như đáp ứng những yêu cầu tín ngưỡng, phong tục... Tục sưởi mộ, tục mở cửa sổ quan tài gốm, chôn theo tinh thể thạch anh trừ tà khí, tục làm biến dạng đồ chôn theo... cũng được người Sa Huỳnh thực hành tuy không phổ biến rộng lắm.

${ }^{2}$ Ở bãi Cọi có hiện tượng chôn chum nằm ngang.

${ }^{3}$ Có người nghiên cứu cho rằng không có tục hoả táng trẻ em, tuy nhiên việc phân tích giới tính, lứa tuổi... đối với tàn tích hoả táng chưa bao giờ được tiến hành, do vậy khó mà đưa ra được kết luận cuối cùng về chủ đề này. 
Cư dân Sa Huỳnh ưa chuộng những đồ gốm trang trí màu sắc tương phản, các họa tiết góc cạnh và uốn lượn thường được tổ hợp tạo thành những băng trang trí chạy ngang trên đồ gốm. Kỹ thuật kết hợp này cùng với chia mảng trang trí xen kẽ giữa mảng để trơn miết bóng với mảng tạo hoa văn và tô màu đã tạo ra hiệu ứng ánh sáng đối nhau trên đồ gốm. Trang trí tô màu hầu hết được kết hợp bổ trợ cho các mô típ hoa văn khác, rất ít hoa văn tô màu đơn lẻ. So với đồ gốm của văn hoá Đông Sơn và văn hoá Đồng Nai giai đoạn Phú Hòa thì đồ gốm Sa Huỳnh đa dạng hơn về loại hình và phong phú hơn về trang trí.

Dựa vào những đồ trang sức tìm thấy chủ yếu trong mộ táng chúng ta có thể thấy cư dân $\mathrm{Sa}$ Huỳnh rất ưa chuộng trang trí cơ thể và trang phục bằng những đồ đeo làm từ nhiều chất liệu từ đất nung, xương, sừng, vỏ nhuyễn thể, san hô, đá quý, thuỷ tinh, kim loại... Đồ trang sức, trang trí gồm từ hai nguồn, nguồn sản xuất tại chỗ và nguồn nhập từ bên ngoài. Loại hình gồm có vòng đeo tay, nhẫn, khuyên tai, vật đeo dạng amulet (bùa may mắn), hạt chuỗi, lục lạc... Khuyên tai hai đầu thú ${ }^{4}$, khuyên tai ba mấu bằng đá và thuỷ tinh được coi là những loại hình trang sức tiểu biểu và độc đáo của các cộng đồng cư dân Sa Huỳnh. Từ góc độ không gian, khuyên tai ba mấu có diện phân bố rộng, hầu như địa điểm nào cũng tìm thấy, khuyên tai hai đầu thú phân bố ở một diện hẹp hơn, ví dụ như vùng lưu vực sông Thu Bồn cho tới nay chưa tìm thấy bất cứ khuyên tai hai đầu thú nào. Những khác biệt không gian này chưa biết có liên quan gì đến ý nghĩa và giá trị biểu trưng cũng như thẩm mỹ của các nhóm người khác nhau hay không.

Đồ chôn theo người chết rất đa dạng và phong phú từ nhiều chất liệu, gốm, đá, đá quý, thuỷ tinh, vàng, đồng, sắt... Vào thời kỳ cuối, khi xã hội đạt mức độ phức hợp cao, nhiều khu mộ địa của thương nhân, mộ táng của dòng họ quý tộc, mộ thủ lĩnh đã hình thành, vị thế của người chết được biểu thị qua độ lớn của ngôi mộ (kích thước mộ, kích thước quan tài), số lượng, chất lượng đồ chôn theo (Lâm, 2018).

\subsection{Nguồn gốc và chủ nhân}

\subsubsection{Nguồn gốc}

Các loại hình văn hoá $\mathrm{Sa} H u y ̀ n h$ bắc và $S a$ Huỳnh nam hình thành dựa trên những nền tảng văn hoá tiền sử hậu kỳ Đá mới - sơ kỳ Kim khí ngay tại chỗ. Một trong những nguồn sớm nhất đó là nhóm di tích giai đoạn muộn của văn hoá Bàu Tró, các nhà nghiên cứu đã chỉ ra những yếu tố Bàu Tró tham góp vào sự hình thành văn hoá $\mathrm{Sa}$ Huỳnh, theo chúng tôi chủ yếu là loại hình Sa Huỳnh bắc. Những di vật biểu hiện mối quan hệ này là bôn răng trâu, gốm tô màu đỏ và đen (Hà, 1997, tr. 736-739). Với những phát hiện ở cồn Nền và một số địa điểm khác thuộc văn hoá Bàu Tró ở Quảng Bình, chúng tôi cho rằng giai đoạn cực muộn của văn hoá Bàu Tró thực ra đã thuộc phạm trù văn hoá tiền $S a$ Huỳnh với đầy đủ những đặc trưng về đồ đá đồ gốm và táng thức mộ chum.

${ }^{4}$ Có người gọi là bùa đeo hay vật đeo. 
Các nhóm tiền Sa Huỳnh như Bình Châu và Long Thạnh là những nguồn chính tạo nên diện mạo của văn hoá Sa Huỳnh, mặc dù vẫn còn những băn khoăn về trật tự sớm muộn của các nhóm. Những văn hoá tiền $S a$ Huỳnh này trực tiếp phát triển lên văn hoá Sa Huỳnh bắc, trong khi những địa điểm giai đoạn Bình Châu cho thấy mối liên quan chặt chẽ với thời đại đồ đồng miền Bắc Việt Nam, đặc biệt là giai đoạn Gò Mun và Đông Sơn sớm thì các địa điểm giai đoạn Long Thạnh với táng thức mộ chum/vò gốm in mép vỏ sò, tô màu đen lại mang nhiều yếu tố hải đảo.

Văn hoá Xóm Cồn là cơ tầng bản địa chính của văn hoá Sa Huỳnh nam, bên cạnh đó những ảnh hưởng từ bên ngoài đặc biệt là hải đảo ở những thế kỷ sau Công nguyên đã tạo ra một diện mạo văn hoá Sa Huỳnh nam đa dạng và phong phú về táng thức, táng tục hơn so với Sa Huỳnh bắc, và chỉ ở không gian Sa Huỳnh nam truyền thống gốm Sa Huỳnh - Kalanay mới cho thấy những biểu hiện rõ ràng và có lẽ nên xác định lại thuật ngữ này một cách chính xác là truyền thống Hoà Diêm - Kalanay. Cũng cần phải nói thêm rằng giai đoạn muộn của văn hoá Xóm Cồn đã thuộc vào sơ kỳ Đồ sắt, tương đương văn hoá Sa Huỳnh; Những mộ chum ở di chỉ Vĩnh Yên hay dấu vết cư trú giai đoạn muộn ở phức hợp Hoà Diêm cho thấy rõ điều đó.

\subsubsection{Chủ nhân}

Cho đến nay chúng ta có rất ít dữ liệu liên quan đến cổ nhân mặc dù đa số các địa điểm khai quật là mộ táng. Tuy nhiên, do hỏa táng là táng tục phổ biển và do đất cát khô nóng không giúp lưu giữ chất liệu hữu cơ nên di cốt người cổ rất hiếm gặp, đặc biệt là ở loại hình Sa Huỳnh bắc.

Ngôi mộ song táng một nam và một nữ ở Xóm Ốc, đảo Lý Sơn (Quảng Ngãi) được Nguyễn (2017) nghiên cứu và nhận thấy sọ của người nữ có những nét gần gũi với các sọ nữ người Việt, La Bạc Loan và khác xa với các sọ nữ Tây Úc. Các kích thước của xương hàm dưới và răng cũng chứng minh di cốt này gần gũi với những đại diện Mongoloid. Tư liệu về 13 chiếc răng người trong mộ Bình $\mathrm{Ba}$, Cam Ranh, Khánh Hoà cũng mang đặc trưng của người Mongoloid.

Tại Hoà Diêm, những di cốt người trong hai loại mộ (mộ đất và mộ chum) ở phức hợp di tích Hoà Diêm nơi mà niên đại AMS hiệu chỉnh cho thấy có bốn giai đoạn, sớm nhất khoảng năm 2,800BP và muộn nhất là năm 100 - 250AD. Mộ chum chứa gốm kiểu Kalanay và gốm màu cam thuộc niên đại muộn nhất, từ thế kỷ II - IIIAD. Một niên đại AMS phân tích từ răng người trong mộ huyệt đất cho kết quả từ năm 200 - 50BC. Dựa vào đó, các nhà nghiên cứu Hoà Diêm cho rằng mộ huyệt đất tồn tại sớm hơn mộ chum có gốm kiểu Kalanay và gốm màu cam (Mariko \& ctg., 2012, tr. 73). Những nghiên cứu cổ nhân cho kết quả chủ nhân của mộ đất trước Công nguyên duy trì đặc điểm Gen của tổ tiên bản xứ từ thời hậu kỳ Đá mới trong khi chủ nhân của mộ chum niên đại sau Công nguyên có những nét tương đồng với người Đông Nam Á ngoài đảo. Từ những phân tích về tài liệu cổ nhân học, kết hợp với tài liệu khảo cổ học có thể phác thảo sơ bộ về nguồn gốc của cư dân Hoà Diêm. Nhiều khả năng, người cổ Hoà Diêm là một bộ phận của những người Indonesien bản địa sinh sống dọc Trường Sơn ngay từ hậu kỳ Đá mới rải rác ở các tỉnh Kon Tum, Gia Lai, Đắk Lắk, và Lâm Đồng mà các dấu 
vết còn để lại ở các địa điểm khảo cổ học của vùng này. Khoảng gần năm $3,000 \mathrm{BP}$, họ đã tràn xuống vùng đồng bằng ven biển suốt từ Quảng Nam đến Bình Thuận. Trong thời gian đó cũng có những nhóm cư dân khác từ Philippin và Indonesia đi vào và thậm chí cả những cư dân bản địa của Đài Loan đi xuống. Sự pha trộn những dòng Gen ở đây là không tránh khỏi, để dần hình thành nhóm cư dân dọc biển miền Trung Việt Nam, trong đó có cư dân cổ Hoà Diêm (Nguyễn \& Matsumura, 2014, tr. 155).

Kết quả phân tích gene cũng khá trùng với kết quả khảo cổ, Hoà Diêm là một phức hợp di tích nhiều giai đoạn, bao gồm cả cư trú và cả nghĩa địa. Lớp cư trú sớm có nhiều đặc điểm của văn hoá Xóm Cồn trước đó, mộ táng gồm mộ đất và mộ chum. Mộ chum giai đoạn muộn cho thấy mối quan hệ chặt chẽ với Kalanay - Tabon Philippin. Ở Hoà Diêm có những nền tảng văn hóa sớm bản địa. Theo kết quả khai quật tháng 8/2011 của Bảo tàng Lịch sử Quốc gia ${ }^{5}$ cho thấy cùng những đợt sóng văn hoá từ bên ngoài, Nam Á là nền tảng cùng Nam Đảo đến sau.

Ở di tích Giồng Phệt, Cần Giờ, TP. Hồ Chí Minh về di cốt có quan hệ gần gũi nhất với sọ người cổ Mongoloid, rồi đến người Myanmar và cũng gần gũi với nhóm loại hình Đông Nam Á của cư dân Đông Sơn. Còn ở Giồng Cá Vồ sọ nữ cho thấy giống những sọ nữ thuộc nhóm loại hình Đông Nam Á của văn hoá Đông Sơn và với sọ nữ La Bạc Loan (Mongoloid Nam Á) ở huyện Quý, Khu Tự trị Dân tộc Choang (Quảng Tây, Trung Quốc) thuộc giai đoạn sơ kỳ Tây Hán (Nguyễn, 2017, tr. 45). Trong một nghiên cứu của Bellwood $(2017$, tr. 106) cho thấy rằng, trái ngược với quan điểm chung từ trước tới nay cho rằng Giồng Cá Vồ vốn là cảng biển và liên quan đến cư dân nói tiếng Nam Đảo, những mẫu nghiên cứu lại cho thấy mối liên hệ với Đông Á lục địa hơn là Đông Nam Á hải đảo. Tuy nhiên, do số lượng mẫu hạn chế và tinh chất cảng biển có nhiều nhóm dân cư, thương nhân bên ngoài, cư dân địa phương nên kêt quả mẫu ở Giồng Cá Vồ nói trên có thể giải thích được.

\section{KẾT LUẬN}

Sau 110 năm phát hiện và nghiên cứu, có thể điểm lại những thành tựu và vấn đề chính đạt được và nảy sinh trong nghiên cứu văn hoá Sa Huỳnh dưới đây:

- Xác định rõ không gian phân bố của văn hoá Sa Huỳnh đồng thời nhận diện các loại hình khu vực của văn hoá Sa Huỳnh. Trong những nghiên cứu này bên cạnh nhận diện di tích và di vật theo các phương pháp truyền thống đã áp dụng thêm nhiều cách tiếp cận của khảo cổ học môi trường, khảo cổ học kỹ thuật, khảo cổ học mộ táng và cái chết, khảo cổ học thương mại... để xác lập được "bản đồ phân bố của văn hóa Sa Huỳnh, không gian phân bố của văn hóa Sa Huỳnh được mở rộng theo cả hai chiều Bắc - Nam, Đông - Tây" (Lâm, 2009b, đoạn 3), khái niệm "Bức khảm văn hoá Sa Huỳnh" được đưa

${ }^{5}$ Có ba nhóm mộ với các đặc trưng cơ bản khác nhau, thuộc các giai đoạn từ sớm đến muộn. Nhóm mộ sớm nhất (hai mộ chum), chôn vào sinh thổ, không có đồ tuỳ táng, chất liệu, màu sắc và loại hình chum gốm rất độc đáo và cơ bản khác biệt so với các mộ còn lại. 
ra với hàm ý tính đa dạng, đa sắc về cả tự nhiên, về cả văn hoá nhưng vẫn thống nhất trong những khía cạnh chính (Lâm, 2018);

- Làm rõ nguồn gốc của văn hoá Sa Huỳnh, đánh giá vai trò của những nguồn văn hoá bản địa như nền tảng cơ bản hình thành văn hoá này trong lúc xác định vai trò thúc đẩy của những yếu tố ngoại sinh và đặt văn hoá Sa Huỳnh trong bối cảnh Đông Nam Á theo cả hai chiều kích lịch đại và đồng đại. "Nguồn gốc văn hóa Sa Huỳnh được xác định theo diễn tiến tiền Sa Huỳnh Sa Huỳnh, văn hóa Sa Huỳnh được xác định qua nhũng chưng cú xác thực có nguồn gốc nội sinh tù hợp nguồn của các dòng chảy văn hóa hậu kỳ Đá mói - so kỳ Kim kĥ̉" (Lâm, 2009b, đoạn 4) (văn hoá Bàu Tró ở bắc Trung Bộ, Long Thạnh - Bình Châu ở trung Trung Bộ, văn hoá Xóm Cồn ở nam Trung Bộ...), tính đa dạng của văn hoá Sa Huỳnh bắt nguồn từ đây;

- Dựa vào kết quả khai quật trên diện rộng và hệ thống một số địa điểm văn hoá Sa Huỳnh như Bãi Cọi (Hà Tĩnh); Cồn Ràng (Huế), gò Mả Vôi, Lai Nghi, Hậu Xá, Bình Yên, Đại Lãnh... (Quảng Nam), gò Quê, Bình Châu II, Xóm Ốc... (Quảng Ngãi); Động Cườm (Bình Định); Hoà Diêm (Khánh Hòa); Phú Trường (Bình Thuận)... nhiều vấn đề của văn hoá Sa Huỳnh như cơ cấu kinh tế, tổ chức xã hội, ngành nghề thủ công, đời sống tinh thần, quan hệ giao lưu kinh tế văn hoá... dần được làm sáng tỏ. Trong giai đoạn này những nghiên cứu được công bố dưới nhiều dạng khác nhau như báo cáo khoa học, trong các thông báo khoa học, bài nghiên cứu trên các tạp chí khoa học trong và ngoài nước, một số đề tài dự án liên quan đến văn hóa $\mathrm{Sa}$ Huỳnh, đặc biệt là một số cuộc hội thảo mang tính quốc gia về văn hóa $\mathrm{Sa}$ Huỳnh, như: Hội thảo "90 năm phát hiện và nghiên cứu văn hóa Sa Huỳnh" được tổ chức ở Hà Nội năm 1999, Hội thảo "100 năm phát hiện và nghiên cứu văn hóa Sa Huỳnh" tổ chức ở Quảng Ngãi năm 2009, một số cuộc hội thảo về văn hóa Sa Huỳnh ở địa phương như ở Hội An năm 2004... các vấn đề nghiên cứu văn hóa $\mathrm{Sa}$ Huỳnh ngày càng sáng tỏ (Bảo tàng Lịch sử Quốc Gia Việt Nam, 2014; Hoàng, 2015; Lâm, 2018; Nguyễn, 2017; Nguyễn \& Matsumura, 2014; \& Vũ, 1991).

Vấn đề đặt ra là, bên cạnh những thành tựu đạt được thì nghiên cứu văn hóa Sa Huỳnh nói chung còn nhiều vấn đề hạn chế đó là nhiều nguồn tư liệu chưa được khai thác hết, nhiều vấn đề được nghiên cứu chuyên sâu song nhiều khía cạnh vẫn chưa được khai thác bởi những nguyên nhân khách quan cũng như chủ quan. Bên cạnh đó, ngoài những tư liệu đã công bố thì việc so sánh đối chiếu với những tư liệu hiện vật được lưu giữ tại các địa phương còn nhiều khó khăn. Việc áp dụng những phương pháp khoa học kỹ thuật, khoa học tự nhiên trong phân tích di vật còn rất khiêm tốn, văn hoá Sa Huỳnh không phải lúc nào cũng được đặt trong bối cảnh của khu vực để thấy được những nét chung và riêng, tiếp cận từ góc độ lịch sử ngôn ngữ, nhân chủng và môi trường cổ... Những hạn chế trên một phần do tư liệu không có và một phần do chưa thấy được sự cần thiết của tiếp cận liên ngành, niên đại tuyệt đối của văn hoá Sa Huỳnh cũng chưa phải đã được quan tâm đúng mức. Nhiều địa điểm chỉ được xác định niên đại dựa vào so sánh loại hình di vật, nhiều khu mộ táng không thể xác định được giai đoạn sớm 
muộn của các mộ táng hay di tích cư trú của cư dân Sa Huỳnh cũng chưa được nghiên cứu hệ thống... Vì vậy, còn nhiều vấn đề được đặt ra và cần giải quyết, cũng như công việc tìm kiếm những phát hiện mới và những nhận thức mới cũng là một nhiệm vụ quan trọng cho nghiên cứu văn hóa Sa Huỳnh hiện nay.

\section{TÀI LIỆU THAM KHẢO}

Bellwood, P. (2017). First islanders: Prehistory and human migration in island southeast Asia. Hoboken, USA: Wiley-Blackwell.

Bảo tàng Lịch sử Quốc Gia Việt Nam. (2014). Di tích Bãi Cọi, Hà Tĩnh, Việt Nam. Trong Báo cáo hợp tác nghiên cúu học thuật Hàn Việt (Quyển 3). Hà Nội, Việt Nam: Bảo tàng Lịch sử Quốc Gia Việt Nam.

Chử, V. T. (2004). Văn hoá Sa Huỳnh - Nhìn lại 10 thập kỷ phát hiện và nghiên cứu. Trong Một thế kỷ khảo cổ học Việt Nam (Tập 1). Hà Nội, Việt Nam: NXB. Khoa học Xã hội.

Francis, P. (2004). Some notes on beads in Vietnam. Retrieved from http://www. thebeadsite.com/SEAC1-03.html

Hà, V. T. (1994). Văn hoá Đông Sơn ở Việt Nam. Hà Nội, Việt Nam: NXB. Khoa học Xã hội.

Hà, V. T. (1997). Theo dấu các văn hoá cổ. Hà Nội, Việt Nam: NXB. Khoa học Xã hội.

Hán, V. K., Hoàng, V. K., Lâm, T. M. D., Nguyễn, X. M., Nguyễn, C., \& Nguyễn, K. S. (2009). Co sở khảo cổ hoc. Hà Nội, Việt Nam: NXB. Đại học Quốc gia Hà Nội.

Hoàng, T. Q. (2008). Đồ gốm trong văn hoá Sa Huỳnh. (Luận văn Thạc sĩ), Viện Khảo cổ học, Việt Nam.

Hoàng, T. Q. (2015). Kỹ thuật chế tác đồ gốm văn hoá Sa Huỳnh. (Luận án Tiến sĩ), Viện Khảo cổ học, Việt Nam.

Lâm, T. M. D. (2003). Về truyền thống mộ chum. Tạp chí Khảo cổ học, (2), 48-59.

Lâm, T. M. D. (2007). Văn hóa Sa Huỳnh tù nhũng phát hiện và nghiên cứu mói. Bài báo được trình bày tại Hội thảo Quốc tế "100 năm phát hiện và nghiên cứu văn hóa Sa Huỳnh”, Quảng Ngãi, Việt Nam.

Lâm, T. M. D. (2008). Nghiên cứu quá trình chuyển biến tù Sơ sủ sang So kỳ Lịch sủ ở miền Trung Trung bộ và Nam Trung bộ Việt Nam. (Đề tài nghiên cứu khoa học trọng điểm cấp Đại học Quốc gia, Mã số ĐTT Đ 06.07). Hà Nội, Việt Nam: Đại học Khoa học Xã hội và Nhân văn, Đại học Quốc gia Hà Nội.

Lam, T. M. D. (2009). Sa Huynh regional and inter-regional interactions in the Thu Bon valley, Quangnam province, central Vietnam. BIPPA (Indo - Pacific Prehistory Association Bulletin), 29, 68-75.

Lâm, T. M. D. (2009). Văn hóa Sa Huỳnh. Được trích lục từ http://dzunglam. blogspot.com/2009/07/van-hoa-sahuynh.html. 
Lâm, T. M. D. (2009c). Tiếp cận khảo cổ học xã hội và khảo cổ học mộ táng. Được truy lục từ http://dzunglam.blogspot.com/2009/10/tiep-can-khao-co-hoc-xa-hoi-vakhao-co.html.

Lâm, T. M. D. (2013). Bối cảnh Đông Nam Á thời tiền sủ. Được truy lục từ https://nghiencuulichsu.com/2013/05/20/boi-canh-dong-nam-a-thoi-tien-su/

Lâm, T. M. D. (2018). Sa Huỳnh - Lâm Âp - Champa thế kỷ V TCN đến thế kỷ V CN. Trong Một số vấn đề khảo cổ học. Hà Nội, Việt Nam: NXB. Thế giới.

Lê, B. T. (1998). Việt Nam lãnh thổ và các vùng địa lý. Hà Nội, Việt Nam: NXB. Thế giới.

Mariko, A., Bùi, C. H., Nguyễn, K. D., Nguyễn, K. T. K., Đặng, N. K., Kanji, T., Shinya, W., Tomomi, S., Emiri, M., Ayako, I. (2012). Báo cáo khai quật di chỉ khảo cổ học Hoà Diêm (Khánh Hoà, Việt Nam). Institute of International Culture Bulletin, (17), 73.

Nguyễn, L. C., \& Matsumura, H. (2014). Nghiên cúu nhũng di cốt người cổ di chỉ khảo cổ học Hoà Diêm, Khánh Hoà. Hà Nội, Việt Nam: NXB. Văn hóa Thông tin.

Nguyễn, L. C. (2017). Những phát hiện về di cốt người cổ trên đảo và ven bờ biển Việt Nam. Trong L. T. M. Dung \& Đ. H. Sơn, Kỷ yếu Hội thảo Khoa học "Khảo cổ hoc Biển Đảo Việt Nam, Tiềm năng và Triển vọng”. Hà Nội, Việt Nam: NXB. Đại học Quốc gia Hà Nội.

Nguyễn, K. D. (2017). Đồ trang sức cổ văn hoá Sa Huỳnh. Hà Nội, Việt Nam: NAFOSTED.

Solheim, W. G. (1959). Sa Huynh pottery relationships in Southeast Asia. Asian Prespectives, 102(2), 47-50.

Vũ, Q. H. (1996). Văn hoá Xóm Cồn và vị trí của nó trong thời đại Kim khí ven biển miền Trung. (Luận án Phó Tiến sỹ), Viện Khảo cổ học, Việt Nam

Vũ, C. Q. (1991). Văn hóa Sa Huỳnh. Hà Nội, Việt Nam: NXB. Văn hóa Dân tộc. 